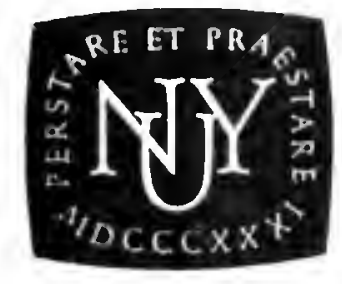

NEW YORK UNIVERSITY

\title{
Bifurcation Buckling of Spherical Caps
}

\author{
EDW ARD L. REISS
}

\author{
PREPARED UNDER \\ GRANT NO. DA-ARO-(D)-31-124-G344 \\ WITH THE \\ U.S. ARMY RESEARCH OFFICE \\ AND \\ CONTRACT NO. NONR-285(42) \\ WITH THE \\ OFFICE OF NAVAL RESEARCH
}





\author{
llew York University \\ Courant Institute of lathematical sciences
}

BIFURCATIOA BUCKLIMG OF SPHLRICAL CAPS

Edward L. Reiss

This report represents results obtained at the Courant Institute of Mathematical Sciences, New York University, under the sponsorship of the U.S. Army Research Office, Grant No. DA-ARO-(D)-31-124-G344 and the Office of Naval Research, Contract IIo. Nonr $-285(42)$. Reproduction in whole or in part is permitted for any purpose of the United States Government. 
C. 1 


\section{Abstract}

A nonlinear boundary value problem is considered for the axisymetric buckling of thin spherical shells subjected to uniform external pressure. The uniformly compressed spherical state is a solution of this problem for all values of the pressure. We prove, using Poincaré's method, that for pressures sufficiently near each simple eigenvalue of the linearized shell buckling theory, there is another (buckled) solution of the nonlinear problem. A convergent perturbation expansion is used to analyze the buckled solutions near the eigenvalues. For a limited range of caps, we also prove that one or three buckled solutions bifurcate from the multiple (double) eigenvalues depending on their order. The existence of a "lowest" intermediate buckling is established and precise upper and lower bounds are given on its magnitude.

\section{Introduction}

The surface of a thin elastic spherical cap is subjected to a uniform pressure, $p$, which is directed towards the cap's center of curvature. It is a well known experimental result, see e.g. [l], that as the pressure increases from zero the cap deforms only slightly from the spherical shape until a critical pressure $\mathrm{p}=\mathrm{p}_{\mathrm{A}}$ is reached. Then the cap suddenly jumps, with relatively large deflections, into a non-spherical shape which we call the buckled state. The fundamental problem of shell buckling is to determine the mechanism wnich initiates the jumping and to obtain estinates of $\mathrm{p}_{\mathrm{A}}$. 

Previous investigatox' $†$ have assumed, as an approximation to exporimental conditions, that the cap's edge is rigialy clamped, i.e. the displacement and chance of slope are zero. In this paper edge conditions are considered ror which the spherical shape (the unbuckled solution) is a possible solution of the nonlinear problem for all pressures. We refer to these as bifurcation bucking problems since other (buckled) solutions of the nonlinear problem may branch from the unbuckled solution.* For example, a bifurcation buckling problem, which We call problen $B$, is obtained if the following conditions are specified on the edge of the cap: no rotation (clamped); zero transverse shear force, $i . e$, the edge is free to move normal to the spherical surface; and the meridional membrane stress is prescribed so that it is in equilibrium with the applied surface pressure. Other bifurcation problems are obtasned, for example, by replacing the condition on the meridional stress in Problem $B$ with a corresponding one on the meridional membrane displacement, or by permitting the cap to freely rotate instead of clamping it. The bifurcation problems are precisely formulated in section 2. In sections 3, 4 and 5 only Problem B is considered. However analogous results can be established for other bifurcation problems. Some of these are contained in the final section of the paper. We consider

I see e.g. [1-7] and references contained therein.

* For the rigidly clamped cap, which we refer to as relaxation buckling, the spherical shape is a solution if and only if $\mathrm{p}=0$. 

only axisymmetric deformations of the cap.

Bifurcation buckling problems for spherical caps were first considered in an approximate form in [8]. An equivalent of Problem $B$ was treated in [5] where the linearized buckling theory was partially analyzed and approximate solutions of the nonlinear problem were obtained. The linear buckling theory had been previously discussed.*

The precise knowledge of the unbuckled state for the bifurcation problems, permits us to rigorously establish certain properties of the solution. In section 3 we prove that for all $P$ sufficiently near each simple eigenvalue of the linearized shell buckling theoryt, a solution of the nonlinear problem exists. Only one solution of the nonlinear problem branches from each simple eigenvalue. A related result is established in section 4 for the other eigenvalues, which are all double, and for a linited range of caps. However, we find the surprising result that one or three solutions of the nonlinear problem bifurcate from the double eigenvalues depending on their order. The conjectured load-deformation curves for simple eigenvalues are sketched in Fig. 1. A perturbation expansion, which is valid near each eigenvalue, is used to prove that the curves in Fig. I have the form of the solid portion.

Our method of analysis is the Poincaré bifurcation theory used to prove the existence of periodic solutions of

Privately commicated to the author by $W$. Squires, 1958. Here $P$ is a dimensionless parameter proportional to $p$, seo Eq. (2.2a) below. 

initial value problems. Previous applications of this technique to boundary value problems are given in $[9,10]$ where related bucking problems for columns and circular plates are studied. In section 3, where the simple eicenvalues are studied, the procedures employed are closely related to those Eiven in [10]. Modifications are made in section 4 to investigate the double eicenvalue case.

Friedrichs [1I] proposed an energy mechanism and introduced the concept of an intermediate buckling load to explain the experimentally observed juiping of comlete spheres from an unbuckled to a buckled state. Modifications and extensions of these ideas were subsequently proposed in [12]. As applied to the bifurcation buckling of caps, see e.g. Fig. I, several intermediate buckling loads $\mathrm{P}_{\mathrm{M}}^{(n)}$ corresponding to different branches of the solution may exist. For a given branch, say bifurcating from the eigenvalue $P_{n}, P_{M}^{(n)}$ is defined as a load in the interval $\mathrm{P}_{\mathrm{L}}^{(n)}<\mathrm{P}_{\mathrm{M}}(\mathrm{n})<\mathrm{P}_{\mathrm{n}}$ such that for all $\mathrm{P}$ in $\mathrm{P}_{\mathrm{L}}^{(n)} \leq \mathrm{P}<\mathrm{P}_{\mathrm{M}}^{(n)}$ the unbuckled state has less potential energy than the corresponding buckled state and conversely for $P$ in $P_{M}^{(n)}<P<P_{n}$. In section 5 we establish, assuming that the potential energy has a minimum for every finite $P$ and $P>0$, the existence of a lowest intermediate buckling load $\mathrm{P}_{M}$, seo Fig. 1. It is shown to be bounded from below by the lowest buckling load of an "equivalent" flat circular plate buckling problem and bounded from above by the lowest eicenvalue, $\underline{P}$, of the linearized shell buckling theory. More accurate upper bounds, which are considerably less than $\underline{\underline{P}}$, are rigorously 

obtained in section 5 by a minimization procedure. These bounds bracket $P_{M}$ for a limited rance of caps. It seems likely that with suitable modifications corresponding estimates of intermediate buckling loads can be obtained for the unsymmetric buckling of spherical caps and other shell bifurcation buciling problems. Some of the results of section 5 are closely related to ones previously announced by Vorovich [13].

\section{Formulation of the Boundary Value Problem}

The elastic spherical cap is of thichness $2 \mathrm{~h}$ and radius $R$ and has a small angle of opening 2A; see Fig, 2 for the shell geometry. We consider the axisymmetric deformations of the cap that result from a uniform and inwardiy directed pressure $p$. The non-vanishing mid-surface displacements, $u$ and $w$ which are in the meridional and nomal directions to the shells mid-surface are therefore functions only of the polar angle $\theta$. Both $w$ and $p$ are counted positive when directed towards the center of curvature. Nonlinear differential equations which describe the small finite axisymetric deformations of thin spherical caps have been derived by several authors, e.E. $[1,2,14-16]$. These equations may be written as,

$$
\begin{array}{ll}
\text { (2.1a) } G f(x)+\lambda f(x)=f g(x)[f(x)+1], \\
\text { (2.1b) } G g(x)=-P\left[f^{2}(x)+2 f(x)\right] .
\end{array}
$$



Here we have used the dimensionless variables:

$$
x \equiv \theta / \Lambda, f(x) \equiv \frac{1}{R \theta} \frac{\operatorname{din}(\Theta)}{d \theta}, p=\left(\Lambda^{2} / C\right)(R / h),
$$

$(2.2 a)$

$$
P \equiv(R / h)^{2}(p / 2 E C), \quad \lambda \equiv P P, \quad C^{2} \equiv 2 / 3\left(1-v^{2}\right),
$$

and the linear differential operator $G$ which is defined by

$$
G \phi(x) \equiv x^{-3}\left[x^{3} \phi^{\prime}(x)\right]^{\prime},
$$

where a prime indicates differentiation with respect to $x$. Here $\mathrm{E}$ is Young's modulus and $\nu$ is Poisson's ratio.*

The "excess" stress function $g(x)$ in (2.I) is defined such that the meridional and circumferential membrane stresses $\sigma_{\ominus}$ and $\sigma_{\phi}$ and the corresponding dimensionless stresses $\Sigma_{\theta}$ and $\Sigma_{\phi}$ are eiven by

$$
\Sigma_{\theta}(x) \equiv(R / h)(2 / E C) \sigma_{\theta}(\theta)=G(x)-P,
$$

$(2.2 b)$

$$
\Sigma_{\phi}(x) \equiv(R / h)(2 / E C) \sigma_{\phi}(\theta)=[x g(x)-x P]^{\prime} \cdot
$$

The outer surface bending stresses $0_{0}^{\circ}$ and $0_{\phi}^{\circ}$, and the corresponding dimensionless stresses $i_{\theta}^{-0}$ and $\tau_{\phi}^{O}$ are given in terms of $f(x)$ by

$$
\Sigma_{\theta}^{0}(x) \equiv(R / h)\left(2 / 3 E C^{2}\right) \sigma_{\theta}^{0}(\theta)=x f^{\prime}(x)+(I+v) f(x),
$$

$(2.2 c)$

$$
\bar{L}_{\phi}^{O}(x) \equiv(R / h)\left(2 / 3 E C^{2}\right) \sigma_{\phi}^{0}(\theta)=v x f^{\prime}(x)+(I+\nu) f(x) .
$$

The independent variable $f(x)$ is related to the slope of the deformed middle surface of the cap with respect to the initial spherical shape. Thus if $f(x) \equiv 0$ for a given deformation the deformed middle surface is also spherical. Wo

* The independent variables $a(x)$ and $y(x)$ employed in previous papers $[2,3]$ are related to the present variables by,

$$
a(x)=x[f(x)+1], \quad r(x)=x[g(x)-P] \text {. }
$$



refer to $f$, which is defined in $(2 \cdot 2 a)$, as the geornetrical paraneter and $P$ and $\lambda$ as either pressure or loadine parametors. To corplete the forrulation conditions at the center $x=0$ and the edse $x=1$ are required. From the symmetry of the deformation and the regularity of the membrane and bending stresses at the origin we obtain with aid of (2.1) that,

$$
f^{\prime}(0)=g^{\prime}(0)=0 .
$$

The edge of the cap is restrained from rotating so that,

$$
f(I)=0 \text {. }
$$

In addition, we assume that at $x=1$ the transverse shear force vanishes and $\Sigma_{\theta}(I)$ is specified so tnat the cap is in equilibrium with the applied pressure. This yields the boundary condition

$$
G(I)=0 \text {. }
$$

The bifurcation buckling problem, Problem B, is defined as the boundary value problem consisting of the differential equations (2.1) and the boundary conditions (2.3) and (2.4). Other boundary conditions can be specified at $x=1$ to yield bifurcation buckling problems for clamped caps, e.g.

$$
f(I)=0, \quad g^{\prime}(1)+(1-v) g(I)=0 .
$$


. .

, 
These conditions imply that on the edge the transverse shear force vanishes and the meridional dis lacerent u (or equivalently the horizontal displacerent) is proportional to $P$ The proportionality constant is determined so that the spherical form is a possible solution for all P.

\section{The Existence of Euckled Solutions.}

A solution of problem $B$ that is valid for all finite $P$ and $:$ is the unbuckled solution, $f(x) \equiv g(x)=0$. This corresponds to a state of uniforn compression in which

$$
\bar{L}(x)=\overline{-}(x)=-p
$$

and the deformed midale surface remains spherical.

The existence of buckled states will now be established using Poincaré's method. Specifically, we prove in this section that for every $>0$ and for every positive integer $n$ there exists a buckled solution when $P$ is in a sufficiently small and full interval about the $\mathrm{n}$-th simple eigenvalue, $P_{n}$, of the linearized shell buckling theory. This is in contrast to the bucirled circular plate [10] where the load must be slightly reater than each eigenvalue of the corresponding linear buckling theory. We also show that for $P$ sufficiently near $P_{n}$ the solution has $n-1$ intermal nodes. In the following section the solutions of Problem $B$ near the other eigenvalues of the linearized theory, which are all double, are studied. 

To employ Poincaré's method parameters $\varepsilon$ and and new independent variables $y(x)$ and $z(x)$ are derined by,

(3.Ia) $\varepsilon \equiv \lim _{x \rightarrow 0}[x \rho(x)]^{\prime}, \quad \delta \equiv \varepsilon^{-1} \lim _{x \rightarrow 0}[x g(x)]^{\prime}$,

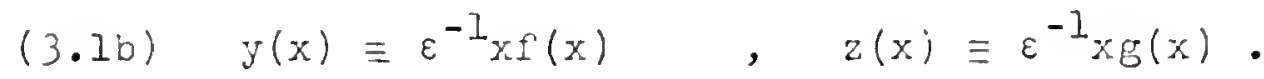

The differential equations (2.1) of Problem $B$ are then given $\mathrm{b}_{\mathrm{j}}$,

(3.2a) $\quad H y(x)+P f y(x)=g(x)[1+\varepsilon y(x) / x]$,

(3.2b) $H z(x)=-\left[\varepsilon y^{2}(x) / x+2 y(x)\right]$,

where $\mathrm{Il}$ is the Iinear differential operator,

$(3.2 c)$

$$
H \phi(x)=\left\{x^{-1}[x \phi(x)]^{\prime}\right\}^{\prime} \cdot
$$

The initial value problem, $*$, is defined by the differential equations (3.2) and the initial conditions:

$(3 \cdot 3 a)$

$$
y(0)=0, \quad y^{\prime}(0)=1,
$$

$(3 \cdot 3 b)$

$$
z(0)=0, \quad z^{\prime}(0)=3 .
$$

For all finite $P, \varepsilon, \bar{b}$ and $\hat{\rho}>0$, Problem has $\varepsilon$ unique solution in the interval $0 \leq x \leq 1$ which is analytic in 
$\therefore$. 
P, $\varepsilon$ and $\delta$. This result can be proved by the same nethods used in [10] to establish an analogous result for the buckling of circular plates and hence the proof is not given here. For fixed $P>0$ values of the parameters $P, E$ and $f$ are sought such that the solution, $[y(x ; P, \varepsilon, \delta), z(x ; P, \varepsilon, \delta)]$ of a satisfies the boundary conditions

$$
y(I ; P, \varepsilon, \delta)=z(I ; P, \varepsilon, \varepsilon)=0 \text {. }
$$

If such a choice of parameters is possible it then follows from (3.Ib) that $f(x)=\frac{\varepsilon y(x ; P, \varepsilon, \therefore)}{x}$ and $g(x)=\frac{\varepsilon z(x ; P \cdot \varepsilon \cdot S)}{x}$ is a solution of $B$.

A solution of which satisfies the boundary conditions (3.4) is obtained by choosing the special parameter value, $\varepsilon=0$ in (3.2). The resulting initial value problem for the functions $y=y(x ; P, 0, \eta), z=z(x ; P, 0, y)$ has solutions which satisfy $(3.4)$ if and only if

$$
\begin{aligned}
& \begin{array}{l}
(3.5 a) \quad P(f)=P_{n}(p)=26 / \frac{2}{n}_{n}^{2} / p \geq 2 \sqrt{2} \\
(3.5 b) \quad \delta(p)=b_{n}(0) \equiv 2 \% \frac{2}{n}
\end{array}
\end{aligned}
$$

where " $n$ is the $n$-th zero of the Bessel function $J_{I}(x)$. The quantities $\mathrm{P}_{n}(\rho)$ are the eigenvalues (or buckling loads) of the linearized buckling theory and they are simple eigenvalues if $P \neq F_{m n}$ and $P \neq P_{n}\left(\hat{m}_{m n}\right)=P_{m}\left(P_{m n}\right)$ where, 


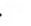


(3.6) $f_{m n} \equiv 2^{-1 / 2} \omega_{m}, m, n=1,2, \ldots, \quad m \neq n$.

The solutions are the eigenfunctions (or buckling modes) of the linearized theory and for simple eigenvalues are given by*

$$
y\left(x ; P_{n}, 0, \delta_{n}\right) \equiv J^{(n)}(x)=\left(A_{n} / \delta_{n}\right) J_{I}\left(\omega_{n} x\right),
$$

$(3.7)$

$$
z\left(x ; P_{n}, 0, \delta_{n}\right) \equiv z^{(n)}(x)=A_{n} J_{I}\left(\rho_{n} x\right)
$$

where

$$
A_{n} \equiv 2 \% n_{n}^{3} J_{I}^{\prime}(0)
$$

The correspondine solutions of Problem $B$ reduce to the unbuckled solution.

Thus for each finite $P>0$ there are a denumerably infinite number of roots $\left[P_{n}, 0, s_{n}\right], n=1,2, \ldots$ of $(3.4)$. According to the implicit function there are other roots of (3.4) near $\left[P_{n}, 0, b_{n}\right]$ if the appropriate Jacobian

(3.8) $J \equiv z_{\delta}^{(n)}(1) y_{P}^{(n)}(1)-z_{P}^{(n)}(1) y_{\delta}^{(n)}(1) \neq 0, \quad n=1,2, \ldots$.

Here we have used the notation

For simplicity, the explicit dependence of the solutions on $p$ is suppressed here and in the remainder of the section. 



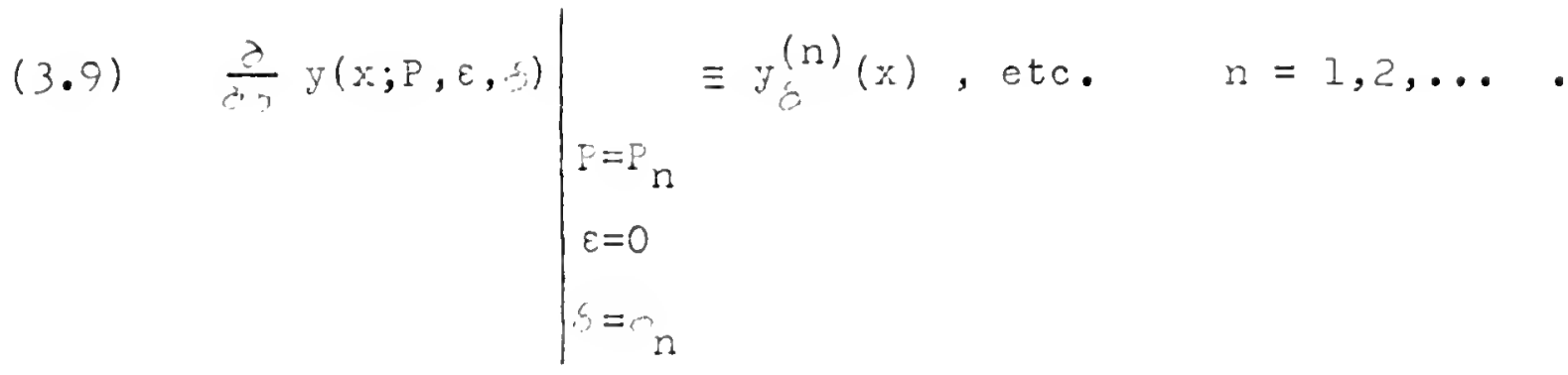

Since $y$ and $z$ are analytic in $P$ and $\delta$, the initial value problems (variational problems) satisfied by $y_{P}, y_{0}, z_{P}$ and $z_{\delta}$ can be obtained by formal differentiation of with respect to $P$ and 5. Thus we obtain from (3.2) and (3.3) using $(3.7)$ and $(3.9)$,

(3.10a) $\mathrm{Hy}_{\mathrm{P}}^{(n)}+\mathrm{P}_{\mathrm{n}} \mathrm{y}_{\mathrm{p}}^{(\mathrm{n})}=\left[\mathrm{z}_{\mathrm{P}}^{(n)}-\mathrm{y}^{(n)}\right], \mathrm{y}_{\mathrm{P}}^{(n)}(0)=\mathrm{y}_{\mathrm{P}}^{(n)^{\prime}}(0)=0$ $(3.10 b) H z_{P}^{(n)}=-2 v_{P}^{(n)}$, $z_{p}^{(n)}(c)=z_{P}^{(n)^{\prime}}(c)=0$ $(3.110)+y_{b}^{(n)}+P_{1}+y_{i}^{(n)}=\rho x(n)$, $y_{\varepsilon}^{(n)}(0)=y_{6}^{(n)^{\prime}}(0)=0$ (3.IIb) $\left.\mathrm{Hz}_{3}^{(n)}=-2 \mathrm{y}\right)$, $z_{j}^{(n)}(0)=0, z^{(n)}(0)=1$ $n=1,2, \ldots$

The explicit solution of (3.11) (not presented) Jields, at $x=1$, the relations

$$
\begin{aligned}
& \because 0 \text { is } \theta \neq m \text { 'm } \\
& \text { (3.12) } 2{ }_{\delta}^{(n)}(1)=2 n_{n}^{-1} y_{b}^{(n)}(1) \quad, m, n=1,2, \ldots, m \neq n \text {. } \\
& =0 \text { if } \rho=F_{m n}
\end{aligned}
$$



Therefore it follows from (3.8) and (3.12) that

(3.13) J $=y_{y}^{(n)}(1)\left[2 \mathrm{n}_{\mathrm{P}}^{-1} \mathrm{y}_{\mathrm{P}}^{(n)}(1)-z_{\mathrm{P}}^{(n)}(1)\right]$.

Hence, $J=0$ if $P=F_{m n}$ and $P=P_{n}$ and nothing can be concluded concerning tne existence of neighboring roots to

$\left[P_{n}\left(f_{m n}\right), 0, h_{n n}\left({ }_{m}\right)\right]$. This case is considered in the following section. To prove that $J \neq 0$ if $P \neq \rho_{m n}, P \neq P_{n}$ we assume the contrary, i.e. Iet,
$(3.14)$
$y_{P}^{(n)}(1)=2^{-1} n_{n}^{2}{ }_{P}^{(n)}$
$(1)=a$

where $a$ is an arbitrary real constant. Then, $\left[y_{p}^{(n)}(x), z_{p}^{(n)}(x)\right]$ is a solution of $(3.10)$ that satisfics the boundary conditions (3.14). A solution of this boundary value problem exists if and only if the inhomogeneous terms are orthogonal to every solution of the homogeneous adjoint problem. This leads to the condition that for all a

$$
\int_{1}^{1} J_{n}^{2}\left(\ln _{n} x\right) x d x=0
$$

which is impossible and hence $J \neq 0$.

Hence, by the implicit function theorem and the analyticity of $y$ and $z$ in the parameters, (3.4) can be uniquely solved for $P$ and $\delta$ as analytic functions of $\varepsilon$ in some sufficiently small neighborhood of each root $\left[P_{n}, 0, S_{n}\right], \rho \neq P_{m n}$. The solutions are the analytic functions 

(3.15) $\quad P=P(n)(\varepsilon), \quad s=\delta_{(n)}(\varepsilon), \quad|\varepsilon|<\varepsilon_{n}, \quad n=1,2, \ldots$,

which satisfy the conditions

$$
P_{(n)}(0)=P_{n}, \quad S_{(n)}(0)=S_{n} .
$$

For sufficiently small $\varepsilon$

$$
f(x ; \varepsilon)=\varepsilon x^{-1} y_{n}(x ; \varepsilon) \equiv \varepsilon x^{-1} y(x ; P(n)(\varepsilon), \varepsilon, \delta(n)(\varepsilon)),
$$

$(3.16)$

$$
g(x ; \varepsilon)=\varepsilon x^{-1} z_{n}(x ; \varepsilon) \equiv \varepsilon x^{-1} z\left(x ; P(n)(\varepsilon), \varepsilon, \delta_{(n)}(\varepsilon)\right)
$$

are solutions of $B$.

The solutions of $B$ near $\varepsilon=0$ are now considered. Since $P(n)(\varepsilon), f_{(n)}(\varepsilon), \mathrm{J}_{n}(x ; \varepsilon)$ and $\mathrm{z}_{n}(x ; \varepsilon)$ are analytic functions there, they have convergent expansions in some interval $|\varepsilon|<\varepsilon_{n}^{\circ}$ given by:

$(3.17)$

$$
P(n)(\varepsilon)=P_{n}+\sum_{i=1}^{\infty} P_{i}^{(n)} \varepsilon^{i}, \quad S_{(n)}(\varepsilon)=\delta_{n}+\sum_{i=1}^{\infty} j_{i}^{(n)} \varepsilon^{i}
$$

$$
y_{n}(x ; \varepsilon)=y^{(n)}(x)+\sum_{i=1}^{\infty} y_{i}^{(n)}(x) \varepsilon^{i}, z_{n}(x ; \varepsilon)=z^{(n)}(x)+\sum_{i=I}^{\infty} z_{i}^{(n)}(x) \varepsilon^{i} .
$$

The expansion coefficients are determined in the usual way by substituting (3.17) into (3.2) and (3.4) and equating the coefficients of each power of $\varepsilon$. Each of the resulting system of linear boundary value problems for the coefficients $\left[y_{1}^{(n)}, z_{i}^{(n)}\right]$ has a solution if and only if the appropriate 
: 
orthogonality condition is satisfied. For the first two of these problems with $i=1,2$ the orthogonality conditions yield

$$
\begin{aligned}
& \text { (3.18a) } P_{I}^{(n)}=\frac{6}{\int_{n}^{3} J_{1}^{1}(0) J_{2}^{2}(\omega)}{ }_{0}^{1} J_{1}^{3}\left(n^{x}\right) d x>0 \text {, } \\
& (3.18 b) \quad P_{2}^{(n)}=\frac{4^{0}}{\left(y_{n} J_{2}\left(\omega_{n}\right)\right)^{2}} \int_{0}^{1}\left[2 y_{1}^{(n)}(x)+\delta_{n}^{-1} z_{1}^{(n)}(x)\right] J_{1}^{2}\left(n_{n} x\right) d x \\
& -\frac{2 J_{I}^{1}(0) \omega_{n} P_{I}^{(n)}}{J_{2}^{2}\left(\omega_{n}\right)} \int_{0}^{I} y_{I}^{(n)}(x) J_{I}\left(\omega_{n} x\right) x d x
\end{aligned}
$$

Thus it follows from the first of (3.17) and (3.18a) that for each $n$ solutions of $B$ must exist for all $P$ in some small interval about $\mathrm{P}_{\mathrm{n}}$.

For sufficiently small $\varepsilon$ we have from (3.17)

$$
y_{n}(x ; \varepsilon)=y^{(n)}(x)+o(\varepsilon)
$$

Hence in the interval $0<x<1, y_{n}$ has the same number of zeros as $y^{(n)}$, or $y_{n}$ has $n-l$ simple zeros. Approximations of the lower buckling load, $P(n) L$, for each branch may be obtained by truncating the series in the first of (3.17) and from the condition that $\frac{\mathrm{dP}(n)(\varepsilon)}{\mathrm{d} \varepsilon}=0$ at the lower buckling load. These approximations may be valid only if the expansions (3.17) converge for sufficiently large $\varepsilon$. For example if 2 terms are retained in the series so that 



$$
P_{n}(\varepsilon) \approx P_{n}+P_{1}^{(n)} \varepsilon+P_{2}^{(n)} \varepsilon^{2}
$$

then

$$
P_{(n) L} \approx P_{n}-\frac{P_{1}^{(n)^{2}}}{4 P_{2}^{(n)}}
$$

4. The Existence of Buckled Solutions liear Double Eigenvalues We now consider $\rho=\rho_{m n}$ and the double eigenvalues,

(4.1) $P=P_{m}\left(P_{n}\right)=P_{n}\left(m_{m n}\right) \equiv m_{n}^{2}+i_{n}^{2}, m, n=1,2, \ldots, m \neq n$.

The solutions of the initial value problem (3.2), (3.3) with $\varepsilon=0, P=F_{m n}$ and $P=P_{m}\left(f_{m n}\right)$, that satisfy the boundary conditions (3.4) are the eigenfunctions*

$$
y\left(x ; P_{m}\left(\rho_{n n}\right), 0, s\right)=y(m n)(x ; s)=\left(a_{m n} / o_{m n}\right) J_{I}\left(\omega_{m} x\right)+\left(a_{n m} / o_{n m}\right) J_{I}\left(a_{n} x\right),
$$

$(4 \cdot 2 a)$

$$
z\left(x ; P_{m}\left(P_{m n}\right), 0, \circlearrowright\right)=z^{(m n)}(x ; \delta) \equiv a_{m n} J_{I}\left(\omega_{m} x\right)+a_{n m} J_{I}\left(\omega_{n} x\right),
$$

where $\delta$ is an arbitrary real number and

$(4 \cdot 2 b)$

$$
\varepsilon_{m n} \equiv 2^{1 / 2} \omega_{n} / \omega_{m} \text {, }
$$

$$
a_{m n}(s) \equiv \frac{2^{1 / 2(n)}}{J_{1}^{1}(0)\left(n_{n}^{2}-J_{m}^{2}\right)}\left[\left(\xi / s_{n m}\right)-1\right] \text {. }
$$

"Here, and in all subsequent equations in this section, the indicies $m, n=1,2, \ldots, n \neq n$, and we shall hereafter omit explicit reference to this. 
The double eigenvalue case may be of especial physical significance. Consider the variation with $p$ of $\underline{P}(\rho)$ which is defined by

$$
\underline{P}(p) \equiv \min _{n} P_{n}(p)
$$

There are local minimums of $\underline{P}(p)$ at $P=2^{3 / 2}, \rho=2^{1 / 2}, \mathrm{n}$, $n=1,2, \ldots$. At $p=p_{n, n+1} \frac{d P}{d \rho}$ is discontinuous or there are "peaks" in the curve of $\underline{P}(f)$ at the double eigenvalues. A corresponding peaking behavior was previously noted $[2,17]$ in the experimental buckling loads obtained by Kaplan and Fung ${ }^{*}[1]$. Although the experimental boundary conditions probably differ from those of Problem $B$, this phenomenon may be related to the occurrence of a double eigenvalue.

Since the Jacobian in (3.8) vanishes if $\rho=P_{m n}$ and $P=P_{n}$, the procedure given in section 3 must be modified to investigate this case. The modifications are essentially extensions of the methods used in the poincaré theory when the variational problem possesses periodic solutions, see [18]. A new parameter $k$ is introduced and modified inftial value problems, $b_{\mathrm{mn}}$, for the functions $\mathrm{y}_{\mathrm{mn}}(\mathrm{x} ; \mathrm{P}, \varepsilon, \delta, \cdots)$ and $z_{m n}(x ; P, \varepsilon, \dot{i}, k)$ are defined by

* For example, the experimental peaks occur at $p \because 20,56$ and $P_{12} \approx 19, f_{23} \approx 50.5$. 



$$
H y_{m n}+P \rho_{m n} y_{m n}-P_{m n} z_{m n}=\varepsilon p_{m n} x^{-1} y_{m n} z_{m n}+k y(m n),
$$

(4.4) $\quad \mathrm{Hz} z_{m n}+2 f_{m n} \mathrm{y}_{m n}=-\varepsilon \mathrm{m}^{-1} \mathrm{y}_{m n}^{2}+\mathrm{kz}(\mathrm{mn})$,

$$
y_{m n}=0, y_{m n}^{\prime}=1, z_{m n}=0, z_{m n}^{\prime}=\delta \text {, for } x=0 .
$$

We can show, as in the preceding section that the unique solution of $f_{\min }$ is an analytic function of the parameters $P, \varepsilon, \delta$ and $k$. The parameter values are to be determined such that the solutions of $\mathcal{L}_{\mathrm{m}}$ satisfy the boundary conditions,

(4.5) $\mathrm{y}_{\mathrm{mn}}(1 ; P, \varepsilon, \delta, k)=z_{\mathrm{mn}}(1 ; P, \varepsilon, \delta, K)=0$.

For the special parameter values $\varepsilon=K=0$ and $P=P_{m}=P_{n}$ the solutions of $\psi_{m n}$ are $\mathrm{y}_{m n}\left(x ; P_{m}\left(\rho_{m n}\right), 0,0_{m n}^{0}, 0\right)=y(m n)\left(x ; r_{m n}^{0}\right)$, $z_{m n}\left(x ; P_{m}\left(P_{m n}\right), 0,0_{m n}^{0}, 0\right)=z^{(m n)}\left(x ; 0_{m n}^{0}\right)$, and they satisfy $(4 \cdot 5)$ for all bounded and real $\xi_{\mathrm{mn}}^{\circ}$. The implicit function theorem is used to determine other roots of $(4.5)$ near each root $\left[\mathrm{P}_{\mathrm{m}}\left(\mathrm{P}_{\mathrm{mn}}\right), 0,-\mathrm{mn}_{\mathrm{m}}, 0\right]$. Proceeding as in section 3 and using the appropriate variational problems we can show that the Jacobian of $(4.5)$ with respect to $P$ and $K$ and evaluated at each root does not vanish for all $\varepsilon_{\mathrm{mn}}^{0} \neq \hat{\sigma}_{\mathrm{mn}}, \hat{\mathrm{n}}_{\mathrm{m}}$. Thus there are solutions of $(4 \cdot 5)$,

$(4.6)$

$$
P=P_{m n}(\varepsilon, \delta), K=K_{m n}(\varepsilon, \delta),
$$



which are analytic functions of $\varepsilon$ and $\sigma$ in some sufficiently small neighborhood of each root $\left[P_{m}\left(P_{m n}\right), 0,0,0\right]$, for which $\delta_{m n}^{0} \neq \delta_{m n}, s_{n m}$ and satisfy the conditions

$$
\text { (4.7) } P_{m n}\left(0,0_{m n}^{0}\right)=P_{m}=P_{n}, K_{m n}\left(0,5_{m n}^{0}\right)=0 \text {. }
$$

Hence the modified problern $(4 \cdot 4),(4.5)$ have solutions

$$
\mathrm{y}_{(m n)}(\mathrm{x} ; \varepsilon, \delta)=y_{m n}\left(x ; P_{m n}(\varepsilon, s), \varepsilon, \delta, k_{m n}(\varepsilon, \varepsilon)\right),
$$

$z_{(m n)}(x ; \varepsilon, \delta) \equiv g_{m n}\left(x ; P_{m n}(\varepsilon, \delta), \varepsilon, \delta, k_{m n}(\varepsilon, \delta)\right)$ which are analjtic in $\varepsilon$ and $\delta$ for sufficiently small $|\varepsilon|$ and $\left|\delta-5_{m n}^{\circ}\right|$.

Solutions of the modified problems are solutions of the original problem $(3.2),(3.3)$ and $(3.4)$ if $\delta$ and $\varepsilon$ are chosen so that the bifurcation equations [18]

$$
K_{m n}(\varepsilon, \delta)=0 \text {, }
$$

aro satisfied. Thus if $(4.8)$ have solutions $\delta=\delta_{\mathrm{mn}}(\varepsilon)$ which satisfy the conditions

$$
\sigma_{m n}(0)=\sigma_{m n}^{0},
$$

then

$(4 \cdot 10)$

$$
f_{m n}(x ; \varepsilon)=\varepsilon x^{-1} y(m n)\left(x ; \varepsilon, \delta_{m n}(\varepsilon)\right),
$$

$$
E_{m n}(x ; \varepsilon)=\varepsilon x^{-1} y(m n)\left(x ; \varepsilon, \delta_{m n}(\varepsilon)\right),
$$

are solutions of Problem B with $=P_{\mathrm{mn}}$.

To investigate the solutions of $(4.8)$ we employ the analyticity of $y, z, P$ and $K$ and expand them in the forms: 



$$
\begin{aligned}
& y_{(m n)}(x ; \varepsilon, \delta)=y^{(m n)}(x ; 0)+\sum_{k=1}^{\infty} y_{k}^{(m n)}(x ; ;) \varepsilon^{k}, \\
& z_{(m n)}(x ; \varepsilon, \delta)=z^{(m n)}(x ; \infty)+\sum_{k=1}^{\infty} z_{k}^{(m n)}(x ; \varepsilon) \varepsilon^{k},
\end{aligned}
$$

(4.11)

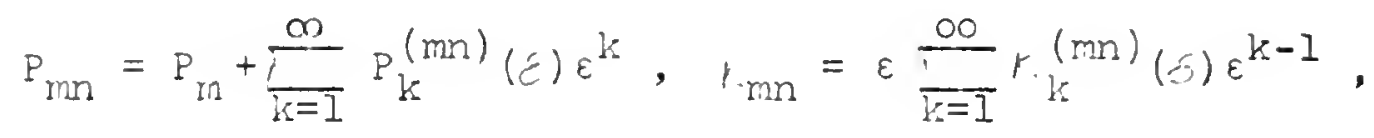

Where we have used the last of (4.7). The series in (4.11) converge in some interval $|\varepsilon|<\varepsilon_{\mathrm{mn}}^{0}$. The coefficients in the expansions are determined by substituting (4.11) into (4.4) and (4.5). The linear boundary value problems for $y_{1}(\mathrm{~m})$ and ${ }_{2}(m n)$, obtained Irom the coefficients of $\varepsilon$, possess solutions, if and only if the inhomogeneous terms satisfy the appropriate orthogonality condition. This condition determines $k(m n)$ and $P_{l}^{(m n)}$ as

$$
{ }_{1}^{(m n)}(\delta)=\left(5_{m n}^{2}-\varepsilon_{n m}^{2}\right)^{-1}\left(\delta_{m n} A_{m n}-b_{n m} A_{n m}\right)
$$

$(4.12)$

$$
P_{1}^{(m n)}(S)=\left(m_{m}^{2}+i_{n}^{2}\right)^{-1}\left(A_{m n}+A_{n n}\right)
$$

where,

$$
A_{m n}=\frac{2 m_{n}^{m} m}{a_{m n} J_{2}^{2}\left(w_{m}\right)} ; 3 c_{m n}^{-2} \phi_{m m} a_{m n}^{2}+2^{-1}\left(4+i_{n m}^{2}\right) \phi_{m n} a_{m n} a_{n m}+\left(\delta_{n m}^{-2}+1\right) \phi_{n m} a_{n m}^{2},
$$

(4.13)

$$
\phi_{m n}=j_{0}^{1} J_{1}^{2}(\cdots x) J_{I}\left(\omega_{n} x\right) d x .
$$



Using the last of $(4.11)$, the bifurcation equations (4.8) reduce to

(4.14) $\quad \sum_{k=1}^{\infty} k_{k}^{(m n)}(\delta) \varepsilon^{k-1}=0$.

If $(4.14)$ have continuous solutions $S=\delta_{m n}(\varepsilon)$ with

$S_{m n}(0)=\sigma_{m n}^{0}$ then $\varepsilon_{m n}^{0}$ must satisfy the bifurcation conditions

$(4.15)$

$$
k_{1}^{(m n)}\left(\delta_{m n}^{0}\right)=0
$$

Conversely, if 0 mn satisfy the bifurcation conditions (4.15) and if

$(4 \cdot 16)$

$$
\frac{d x_{1}^{(m n)}\left(\varepsilon_{m n}^{0}\right)}{d \varepsilon} \neq 0
$$

then the implicit function theorem is applicable to (4.14) and it implies that the bifurcation equations can be solved in some sufficiently small neighborhood of $b=5_{m n}^{0}, \varepsilon=0$. The solutions $\delta=\delta_{m n}(\varepsilon)$ are analytic functions for sufficiently small $\varepsilon$ and satisfy $\delta_{m n}(0)=\zeta_{m n}^{0}$.

Inserting (4.12) and (4.13) into (4.15) and (4.16) and defining $\xi_{m n}$ by

$(4.17)$

$$
\xi_{m n}=\frac{a_{m n}\left(\xi_{m n}^{0}\right)}{a_{n m}\left(\xi_{m n}^{0}\right)}
$$

the bifurcation conditions reduce to the cubics: 

$(4.18)$

$$
\xi_{m n}^{3}+E_{m n} \xi_{m n}^{2}+G_{m n} E_{n m} \xi_{m n}+G_{m n}=0
$$

and the "solvability conditions" (4.16) reduce to:

$$
\text { (4.19) } \xi_{m n}^{4}+2\left(\frac{n}{c_{m}^{4}}\right)^{3} \xi_{m n}^{3}+\left[\left(\frac{n}{\omega_{m}}\right)^{3} E_{m n}-G_{m n} E_{n m}\right] \xi_{m n}^{2}-2 G_{m n} \xi_{m n}-\left(\frac{n}{m}\right)^{3} G_{m n} \neq 0 .
$$

Here we have used the notation,

$$
\left.E_{m n} \equiv \frac{\left(\omega_{m} / \rho_{n}\right)^{4}}{\left(1+s_{m n}^{2}\right) \phi_{m n}} \mid 2^{-1} 2_{n m}^{2}\left(4+s_{m n}^{2}\right) \phi_{n m}-3 \frac{J_{2}^{2}\left(\omega_{n}\right)}{J_{2}^{2}\left(\omega_{m}\right)} \phi_{m m}\right],
$$

$(4 \cdot 20)$

$$
G_{m n} \equiv-\left(\omega_{m} / \omega_{n}\right)^{8} \frac{\left(1+\delta_{n m}^{2}\right)}{\left(1+i_{m n}\right)} \frac{J_{2}^{2}\left(\omega_{n}\right)}{J_{2}^{2}\left(\omega_{m}\right)} \frac{\dot{t}_{m m}}{\phi_{m n}} .
$$

Thus we conclude from (4.18) that for each $m$ and $n$ there is at least one real $\delta_{\mathrm{m}}^{\circ}$ that satisfies the bifurcation condition and $c_{\mathrm{mn}}^{\circ}=5_{\mathrm{mn}}$, ' $\mathrm{nm}$ are not roots of $(4.18)$.

If the explicit values of the integrals $\phi_{m n}$, defined in (4.13) are known then the roots of (4.18) can be determined using standard formulae. These integrals were numerically determined using Simpson's Rule with 500 mesh points* for $m$ and $n$ in the range $I \leq m, n \leq 25$. The Bessel functions were evaluated using the procedure of [19] for arguments between zero and eight and appropriate asymptotic formulae vere used

\footnotetext{
Several of the integrals were evaluated using 1000 mesh points. No significant difference was observed with the results of the 500 point mesh. Double precision arithmetic was employed and all calculations were preformed on the IBM 7094 computer at the AEC Computing and Applied Mathematics Center of the Courant Institute of Mathematical Sciences. The author is indebted to Dr. F. Bauer for conducting the computation.
} 
for larger arguments. We found that all the roots of (4.18), for $m$ and $n$ in the ranget $1 \leq m, n \leq 25$, satisfied (4.19) well within the accuracy of the computation. In fact, the left side of (4.19) was usually quite large. Hence we have shown that there is at loast ore solution of Problem $B$ for $P$ in some sufficiently small neighborhood of each double eigenvalue with $\mathrm{m}$ and $\mathrm{n}$ in the above range. We conjecture that there are solutions near each double eigenvalue for all $m, n=1,2, \ldots$. We also find that for the following indicies $(4.18)$ his three real roots:
1) $n=m+1$,
$3 \leq n \leq 25, n$ odd,
2) $n=m+3$,
$14 \leq n \leq 25, n$ odd,
3) $n=2 m+1$,
$2 \leq n \leq 25$,
4) $n=2 m+3$,
$6 \leq n \leq 25$,
5) $n=2 m+5$,
$8 \leq n \leq 25$.

Thus in a sufficiently small neighborhood of the double eigenvalues with the above indicies there are three solutions of Problem B. Hence, as $P \rightarrow \mathrm{P}_{\mathrm{m}}$ the $\mathrm{m}$-th and $\mathrm{n}$-th branches coalesce and when $P=P_{m n}$ one solution may be "destroyed" or a third solution may be "created" depending on the values of the indicies $m$ and $n$. 



\section{The Intermediate Buckling Load}

It is convenient to reformulate Problem $B$ to establish the existence of the intermediate buckling load $\mathrm{P}_{M}$, or equivalently $\lambda_{M}=P P_{M}$, and to obtain upper and lower bounds on its magnitude. Equation (2.1b) is integrated and the second of (2.3) is used to obtain

(5.1) $g^{\prime}(x)=-1 x^{-3} \int_{0}^{x}\left[f^{2}\left(x_{0}\right)+2 f\left(x_{0}\right)\right] x_{0}^{3} d x_{0}$.

Then, using (2.4b), $g(x)$ is given as a functional of $f(x)$ by

$$
g(x)=\int_{-1}^{x} g^{\prime}\left(x_{1}\right) d x_{1}
$$

The boundary value problem, B, is reformulated as Problem B' as follows: To find a function $f(x)$ which possesses a continuous second derivative and satisfies the differential equation $(2.1 a)$ and the boundary conditions

$$
f^{\prime}(0)=f(I)=0 \text {. }
$$

The function $g(x)$ in $(2.1 a)$ is defined by (5.1) and (5.2). These equations imply that $g(x)$ satisfies (2.1b) and $g^{\prime}(0)=g(1)=0$. This statement of the boundary value problem is similar to the one introduced in [20] in a study of the buckling of circular plates. The "energy" functional $\mathrm{V}$ is defined as,

(5.4) $v[f(x) ; \lambda, f]=\int_{-0}^{1}\left[2\left(f^{\prime 2}(x)-\lambda f^{2}(x)\right)+f^{12}(x)\right] x^{3} d x$, 

where $g^{\prime}(x)$ is considered as a functional of $f(x)$ defined by (5.1). Thus $V$ is a functicnal of $f(x)$ only and it is proportional to the difference between the potential energies of a buckled and the unbuckled state.

The relationship between $B^{\prime}$ and $V$ is obtained by first defining a class of runctions. $f(x)$ is contained in $A$ or is an A-function if in the interval $0 \leq x \leq 1$ it is continuous and satisfies (5.3), $f^{\prime}(x)$ is an $I_{2}$ function and all integrals in (5.1), (5.2) and $(5.4)$ exist. Then it is easy to show that if $\rho(x)$ is a solution of $B^{\prime}$ it makes $V$ stationary with respect to all A-functions. The converse of this result can be proved using the methods outlined in [20]. The converse states that if $f(x)$ makes $V$ stationary (or minimizes $V$ ) then $f^{\prime \prime}(x)$ is continuous and $f^{\prime}(x)$ solves $B$. Here $f_{0}(x) E$ A is said to minimize $V$ for a fixed $\lambda$ and $P$ if $V\left[f_{0}(x)\right] \leq V[f(x)]$ for all $f(x)=A$.

The result concerning the existence of $\lambda_{M}$ is now stated as the

THEORE!I. If for every finite and $\lambda$ there is an A- function which minimizes $V$, then $\lambda_{M}(f)$ exists and it is in the interval ${ }^{2} \leq \lambda_{M}(f)<\underline{\lambda} \equiv C \underline{P}(r)$, where $\underline{P}(f)$ is derined in (4.3), and is the first zero of $J_{I}(x)=0$.

The theorem is a direct consequence of the lemmas given below and the following inequality, which is easily demonstrated using classical methods [21], 

(5.5) $\int_{0}^{1}\left[f^{2}(x)-2^{2} f^{2}(x)\right] x^{3} d x \geq 0$, for all $f(x)=A$.

Here $\omega_{l}^{2}$ is also the lowest eicenvalue of the linearized buckling problem for the symetric deformations of radially compressed and clamped circular plates:

(5.6) $\quad G f(x)+\lambda f(x)=0, \quad f^{\prime}(0)=f(1)=0$.

We call (5.6) the "equivalent" circular plate problem. The inequality (5.5) and the functional $V$ given in (5.4) and (5.1) immediately yield

LEIIA 1. If $\lambda \leq l_{1}^{2}$ then only $f(x) \equiv 0$ minimizes $V$.

The form of the functional $V$ and the properties of the eigenvalues (3.5a) and eigenvectors (3.7) of the linear shell buckling problem yield

LEIIIA 2. If $\lambda=\underline{\lambda}(\hat{\rho})$ then there exist for each $p>0$ a function $f(x) \in A$ such that $V[f(x)]<0$.

The proof of this lemma is obtained by a simple calculation of $V\left[f_{n}(x)\right]$ where $f_{n}(x) \equiv B_{n} J_{l}\left(w_{n} x\right) / x$ are eigenfunctions of the linear theory and $B_{n}$ are constants restricted to lie in the ranges $0>B_{n}>-2 \beta_{n} / a_{n}^{2}, n=1,2, \ldots$. The constants $a_{n}$ and $\beta_{n}$ are defined by

$$
\begin{aligned}
& a_{n}^{2} \equiv \int_{0}^{2}\left[\int_{0}^{x} J_{1}^{2}\left(\omega_{n} x^{\prime}\right) x^{\prime} d x^{\prime}\right] x^{-3} d x, \\
& \beta_{n} \equiv 2 p^{2} \int_{0}^{1}\left[J_{1}^{2}\left(\omega_{n} x^{\prime}\right) x^{\prime} d x^{\prime}\right]\left[\int_{0}^{x} J_{l}\left(\omega_{n} x^{\prime}\right) x^{\prime 2} d x^{\prime}\right] x^{-3} d x>0 .
\end{aligned}
$$



Lemma 1 implies that if $\lambda=\underline{\lambda}$ then E.I.b. $V[f(x)]<0$. The remaining two lemmas show that the set of $\lambda^{\prime} s$ is divided into two disjoint sets: those $\lambda^{\prime}$ s for which the minimum of $V$ is zero and those for which it is negative.

LEMVIA 3. If $f(x)=0$ minimizes $V$ for $\lambda=\lambda_{0}$, then only $f(x) \equiv 0$ minimizes $V$ for alI $\lambda<\lambda_{0}$.

Proof: $T$ We deduce directly from the fom of $V$ that if $\lambda<\lambda_{0}, V \geq 0$ for all A-functions. Suppose there is a $\lambda=\lambda *<\lambda_{0}$ and an A-function $f^{*}(x) \neq 0$ which minimizes $V$, i.e. $V\left[f^{*}(x) ; \lambda^{*}\right]=0$. Then if $\lambda$ is in the range $\lambda^{*}<\lambda<\lambda_{0}$, $V\left[\mathrm{f}^{*} ; \lambda\right]<V\left[\mathrm{I}^{*} ; \lambda^{*}\right]=0$. This is in contradiction to the nonnegative property of $V$ for $\lambda<\lambda_{0}$ and the proof of the lemma is complete.

LEIMA 4. If the minimum of $V$ is negative for $\lambda=\lambda_{0}$ then it is negative for all $\lambda \geq \lambda_{0}$.

Froof: By contradiction using Lemma 3.

The theorem is then proved if we define $\lambda_{M}(\eta)$ as the 1.u.b. of those $\lambda$ for which $f(x)=0$ minimizes $V$. Thus for each $\hat{p}$ there is a $\lambda=\lambda_{\text {II }}$ such that for all $\lambda>\lambda_{M}$ there are buckled states with less energy than the unbuckled state and for $\lambda<\lambda_{M}$ all buckled states have greater energy than the unbuckled state.

The intermediate load can also be characterized by the

This form of the proof was suggested by Dr. I. Newman. 

minimum property,

(5.7) $\quad \lambda_{M}(r)=\min _{f(x)} \neq 0 \in A$

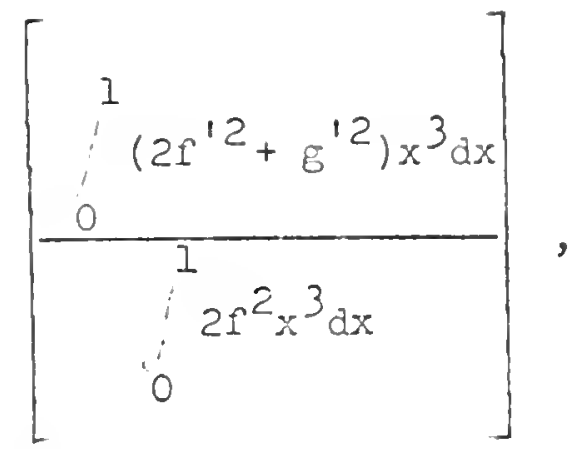

where $g^{\prime}(x)$ is defined in $(5.1)$. Upper bounds for $\lambda_{M}$ are obtained by selecting trial A-functions to make the quotient in (5.7) as small as possible. For example, functions of the form $f(x)=\beta F(x)$ are considered, where $F(x)=A$ is a specified function and $\beta$ is an arbitrary constant. The quotient is then a function of $\beta$ only and $\beta$ is determined to minimize it. Some of the trial functions that were used and the resulting upper bounds, $\lambda_{i n, i}()=a_{i}+b_{i} 10^{-3} p^{2}$, are shown $*$ in Table $I$.

Tabie I

\begin{tabular}{|c|l|c|c|}
\hline & & \multicolumn{2}{|c|}{$\lambda_{M, i}=a_{i}+b_{i} 10^{-3} p^{2}$} \\
\hline$i$ & $F(x)$ & $a_{i}$ & $b_{i}$ \\
\hline 1 & $1-x$ & 15.0 & 6.5166 \\
2 & $1-x^{2}$ & 16.0 & 3.7037 \\
3 & $1-x^{3}$ & 17.50 & 2.4451 \\
4 & $1-x^{4}$ & 19.20 & 1.7166 \\
5 & $1+x-2 x^{2}$ & 16.7576 & 2.7836 \\
6 & $2\left(2-x-x^{2}\right)$ & 15.5054 & 4.6055 \\
\hline
\end{tabular}

"The calculations were performed by $\mathrm{l}$. Szeto. 

The results" are sumarized in $\mathrm{Fig} .3$ where we also show accurate approximations of $\lambda_{11}$ obtained from a numerical solution of Problem B. Details of these and other calculations will be reported elsewhere [22].

\section{Other Bifurcation Problems}

Analogous results can be obtained for other bifurcation buckling problems. For exarple, for the boundary value problem consisting of $(2.1),(2.3)$ and $(2.5)$ which we call Problem $3_{1}$, we can show that

$$
)_{1}^{2} \leq \lambda_{M}(\rho)<\underline{\lambda}(\rho)
$$

Where $\underline{\lambda}$ is now the minimur eisenvalue of the linearized shell buckling theory using the boundary conditions (2.5) in place of (2.4). Upper bounds for $\lambda_{M}(p)$ are obtained from a formula similar to (5.7). These results are craphed in Fig. 3 itth the prediaticns of $\lambda_{M}$ obtained firom a numerical solletion of the bcundang value proviem [22].

$\sigma_{1}^{2} \approx 14.684$ 


\section{References}

[1] Kaplan, A. and Fung, Y. C., A Ionlinear Theory of Bending and Bucking of Thin IIastic Shallow Spherical Shellg, NACA, T.N. 3213 (1954).

[2] Reiss, E. L., Greenberg, H. J. and Keller, H. B,, Ionlinear Deflections of Shallow Spherical Shells, J. Aero. Sci., 24, ppo 533-543 (1957)。

[3] Keller, H. B. and Reiss, E. L., Spherical Cap Snapping, J. A0:c/spaco Sci., 26, pp. 643-652 (1959).

[4] Weinitschke, H. J., On the Stability Problem for Shallow Spherical Shells, J. irath. and Phys., 38, pp. 209-231 (1960).

[5] Budiansky, B., Bucking of Clamped Shallow Spherical Shells, Symp. on Theory of Thin Elastic Shells, Delft, pp. 64-94 (1959).

[6] Murraj, F. J. and Wright, F. W., The Buckling of Thin Spherical_shells, J. Aero/space Scio, 28, pp. 223-236 (1961).

[7] Thurston, G. A., A Nurerical Solution of the Nonlinear Equations for Axisymetric Bendinf of Shallow Spherical Shells, Journ. Appl. Hech., 28, pp. 557-562 (1961).

[8] Reiss, E. L., Axially Symmetric Buckling of Shallow Sphorical Sholls Under External Pressure, J. Appl. Mech., 25, pp. 556-560 (1958). 

[9] Keller, J. B., The Shape of the Strongest Column, Archiv. Ratl. Hech. and Aral., 5, pp.275-285 (1960).

[10] Keller, H. B., Keller, J. B., and Reiss, E. L., Buckled States of Circular Plates, Q. Appl. Math., 20, pp. 55-65 (1962).

[1]] Friedrichs, K. 0., on the Minimum Buckling Load for Spherical Shell.s, von Kármán Anniv. Vol., pp. 258-272 (1941).

[12] Keller, H. B. and Reiss, E. L., Some Recent Pesults on The Buckling Mechanism of Spherical Caps NASA T.N. D-1510 (1962).

[13] Vorovich, I. I., Certain Questions on the Large Deformation Stability of Shells, Soviet Phys. Dokl., 3, pp. 1032-1035 (1958). Translated from Dokl. ANUSSR, 122, pp. 37-40 (1958).

[14] Chien, W. Z., The Intrinsic Theory of Thin Shells and Plates, Q. Appl. Math., 2, pp. 120-135 (1944).

[15] Roissner, E., On Axi-Symmetrical Deformations of Thin Shells of Revolution, Proc. of Symp. on Appl. liath., Amer. Math. Soc., Vol. 3, pp. 27-52, 1950.

[16] Foodosyov, V. I., On Largo Deflnctiong ard Stability of a Clrcular Membrane with Fine Corrugation, (in Russian), Prikl. Mat. Mekh. 10, (1945). 

[17] Reiss, E. L., on the ITonlinear Bucklinf of Shallow Spherical Domes, J. Acro. Sci., 23, pp. 973-975 (1956).

[18] Friedrichs, K. O., Special Topics in Analysis, Lecture notes, Courant Inst. of Math. Sci. New York University, 1953.

[19] Goldstein, $M$. and Thaler, R., Recurrence Techniques for the Calculation of Besse]. Functions, MTAC, 13, pp. 102108 (1959).

[20] Friedrichs, K. O. and Stoker, J. J., The Nonlinear Boundary Value Problem of the Buckled Circular Plate, Amer. Journ. Natí, 63, pp. 839-888 (1941).

[21] Courant, R. and Hilbert, D., Mlethods of llathematical Physics, Vol. I, Interscience, New York, 1953.

[22] Bauer, F., Keller, H. B. and Reiss, E. I., Numerical Studies of the Deformation and Euckling of Spherical Caps, to appear. 



\section{Captions for Figures}

Figure 1. Sketch of conjectured load deformation curve for bifurcation buckline. Here $D$ is a representative deformation, e.f. the nomal displacement of the cap's center.

Ficure 2. Shell geometry.

Figure 3. Intermediate bucliling loads for Problems $B$ and $B *$. The upper bound curves are essentially the envelopes of the curves given in Tables I and II. 



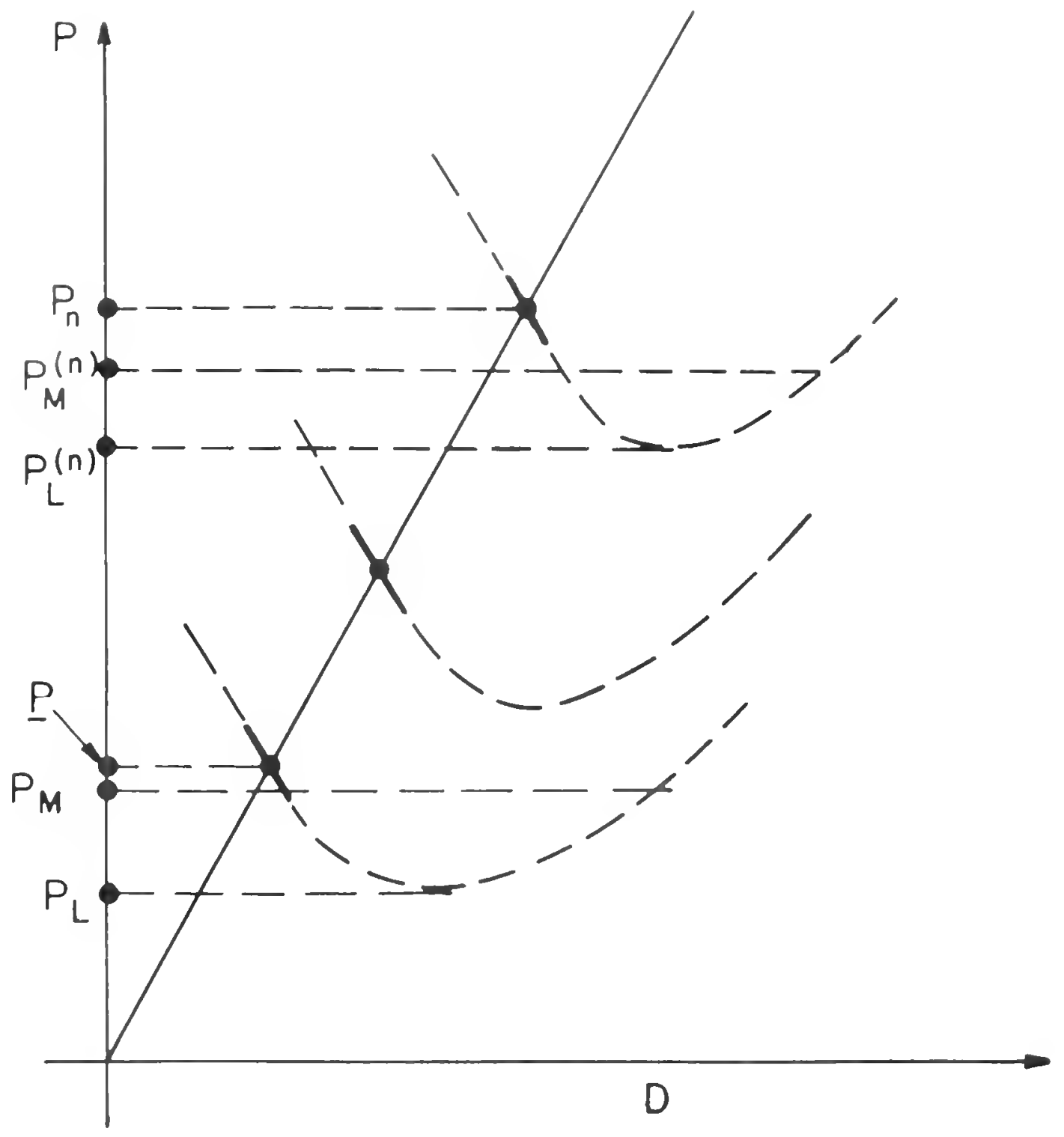

Figure I 



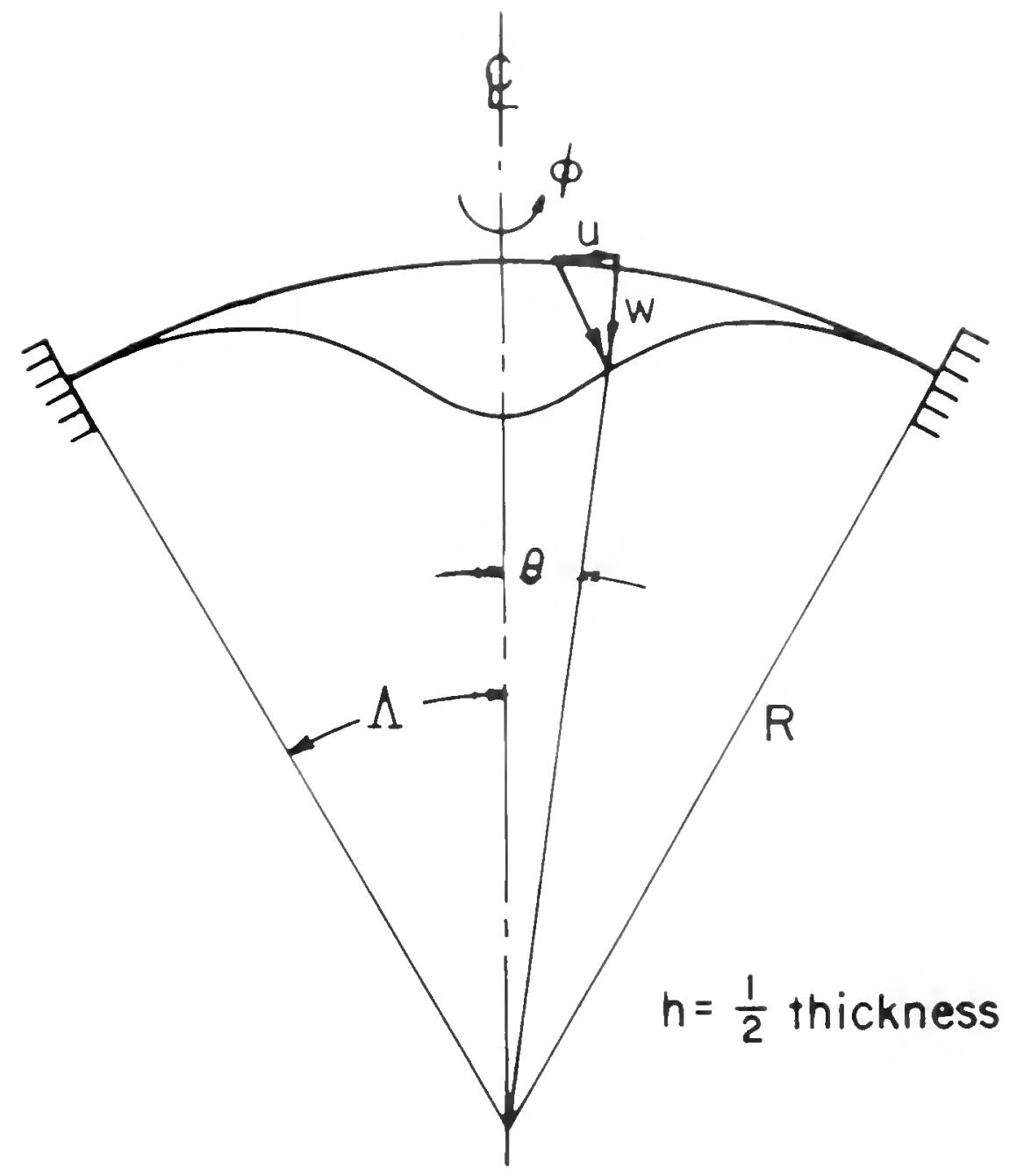

Figure 2 



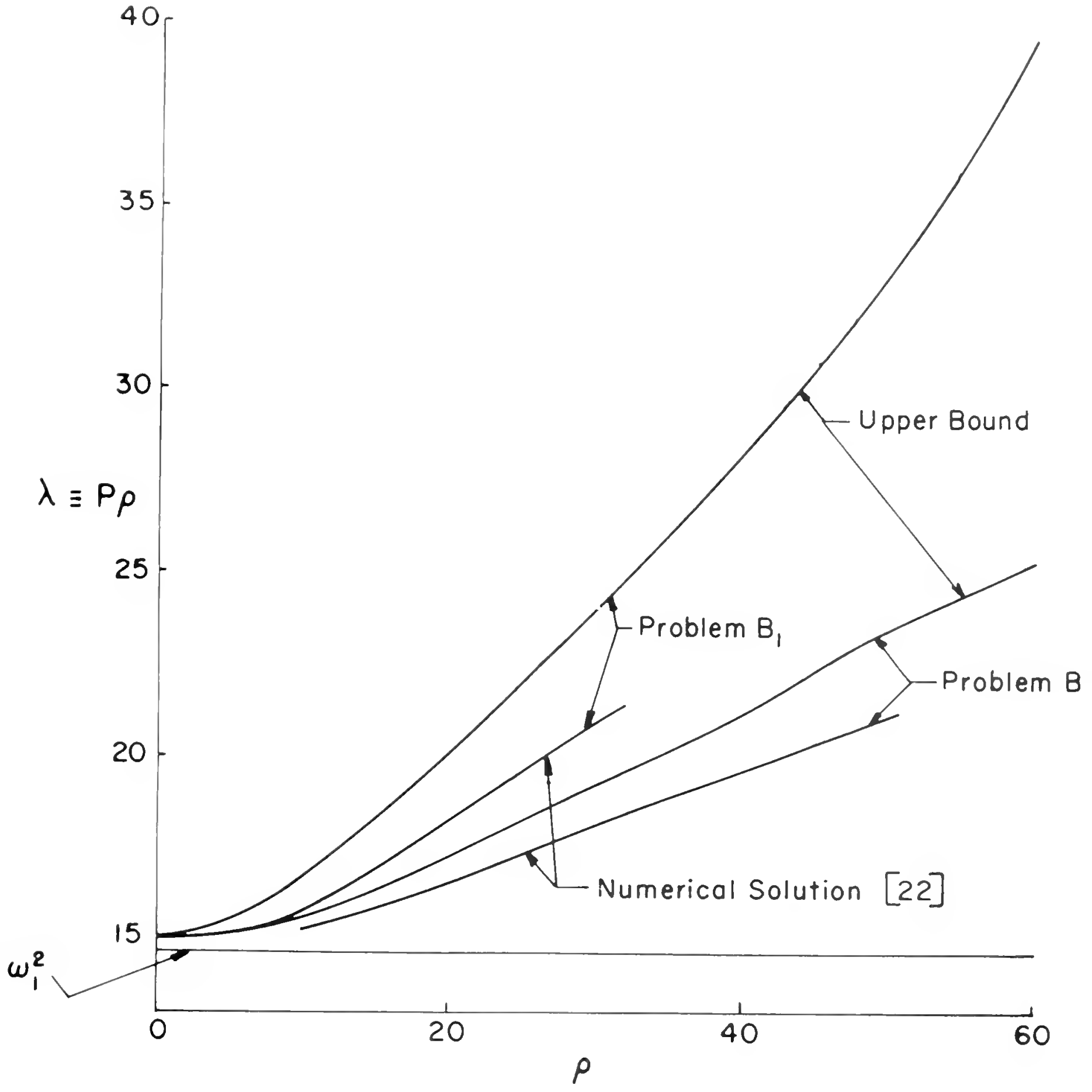

Figure 3 

Chief of llav. Res.

Dept. of Navy, Vashington 25, D.C. Attn: Code 438

Co, Office of llav. Res.

Br. Office, 495 Surner St.

Boston 10, líassac hisetts

Co, Office of llav. Res.

$\mathrm{Br}$. Office, J. Crerar Library

86 E. Randolph St.

Chicago 1l, Illinois

Co, Office of Nav. Res.

Br. Office, 207 Vest 24 th St.

New York 11, N.1.

Co, Office of Hav. Res.

$\mathrm{Br}$. Office, $1030 \mathrm{E}$. Green St.

Pasadena, California

CO, Office of llav. nes.

Br. Office, ivavy 100, Leet ....

New York, W.Y.

Dir., ilav. Res. Labs.

Washington 25, D.C.

Attn: Tech. Info. Officer

Code 6200

Code 6205

Code 6250

Code 6260

ASTIA, Arlington Hall Station

Arlington 12, Virginia

Office of Techn. Services

Dept. of Commerce

Washington 25, D.C.

Dir. of Def. Res, and Engin.

The Pentagon, Washington 25, D.C. Attn: Techn. Library

Chief, Armed rorces Special Weapons Project

The Pentagon, Washington 25, D.C. Attn: Techn. Info. Div. Weapons iffects Liv. Spec. irield Projects

Blast and Shock Br.

Office of secy. of the Army

The Pentagon, ashineton 25, D.C. Attn: Army Library
Cinief of Staff, Dept. of Army

iashinston 25, D.C.

Attn: Dev, Br. (Reii Divo)

Res. Br. (RuD Div)

Spec. ieapons Br. (akd)

Olfice of Chief of Engineers Dept. of Army, lashington 25, 2.C. ittr: E.HG-HL Lib. Br. Adn. Ser. Liv.

ENG-iD Plan Div. Uiv. iks

LIVG-ED Port. Constr. Br., Eng, Div. Hil. Cons. (I)

EirG-IA Struc. Br. Ligg. Div. ili. Constr.

2.is-.1B Spec. Lngr. 35 ,

Eng. FR IIV.

Co, Engin. Tes. Dev. Lab.

Fort selvoir. Virpinia

Office of Chief of ordnance

lept of Amy, washington 25, 2.2.

Attn: ves. and liat. ir.,

$$
\text { (urc. . ing liv.) }
$$

Co, Vatertom Arseral

Atertom, liassachusetts

Attn: Lab. Div.

Co, Frantiord Arsenal

Sridesburg Station

Philacielpiria 37, Penra.

Attn: Lab. Liv.

Office of Ordnance Research

2127 Myrtle Ir., Duke ctation

Durhar, North Carolina

Attr: Div. of Ingin. Sci.

Co, Squier Signal Lab.

rort lionmouth, iv.J.

Attn: Comp. and vat. Br.

Chief of iaval Operations

Dept. of Navy, Washington 25, D.C.

Attn: Op 91

Op OJEG

Commandant, liarine Corps

iieadquarters, UJiC

Vashington 25, D.C.

Office of Chief Signal officer Dept. of imy, lias!rington 25, 1).C. uttn: Engin. and Techn. Div. 

Chief, Buream of Ships

Dept. of Navy

Washington 25, D.C.

Attn: Code 106

Code 312

Code 320

Code 370

Code 375

Code 420

Code 421

Code 423

Code 425

Code 4.0

Code 442

Code 443

Code 525

code 633

(1)

(5)

(1)

(1)

(I)

(I)

(1)

(2)

(1)

(2)

(1)

(1)

(1)

Chief, Buream of Aeronautics

Dept. of Navy

Washington 25, D.C.

Attn: $A E-4$

AV -34

AD

$A D-2$

RS -7

RS-8

SI

AER-126

(1)

(1)

(1)

(I)

(I)

(I)

(1)

(1)

Chief, Juream of Ordnance

Dept. of liavy

Washington 25, D.C.

Attn: Ad3

Re

Res

Kei

Res5

ReSI

Ren

(1)

(1)

(1)

(1)

(1)

Spec. Proj. Office, 3ur. urd.

Dept. of Wavy

Vashington 25, 2.C.

Attn: Missile $3 r$.

Chief, Bur. Yards and Docks

Dept. of liavy

Washington 25, D.C.

Attn: Code D-202

Code $\mathrm{N}-202.3$

Code 220

Code D-222

Code D-4IOC

Code D-L40

Code D-500
Comanding ufficer and Director

David Taylor lodel 3asin

liashington 7, D.C.

Attn: Code 140

Code 600

Code 700

Code 720

Code 725

Code 731

Code 740

(1)

(1)

(1)

(2)

CO, U.S. Haval Ordnance Lan.

White Oak, Haryland

Attn: Techn. Licrary

Techn. Eval Lept.

Director, Naterials Lab.

H.Y. Haval Shipyard

Brooklyn 1, A. .

co, Portsmouth liaval Shipyard

Portsnouth, Vew liampshire

co, ware Island Itav. Shipyard

ballejo, Lalifornia

Co and Lirector

U.S. Nav, iectron. Lab.

San viego 52, Cilifornia

Oricer-in-charge

Nav. Civ. Engin, Res. and Eval. Lab.

U.S. Hav. Constr, Battal. Center

Port Huenene, California

Dir., Nav. Air Lxperimental Sta. ivav. Air lat. Center, Mv. Zase

Philadelphiz 12, Penna:

Attr: liaterials Laj.

Structures Lab.

Officer-in-Charge

Underwater Lxplos. Res. Div.

Norfolk liaval Shipjard

Portsmouth, Virginia

Attn: or. A.H. Keil

CO, U.S. Nav. Proving Ground

(1) Dahigren. Virginia

Supr. of Shipbuilding

(1)
USN and Vav. Insvec. of Ordnance

General Ijtamics Corpo,

ilectr. Boat jiv.

Groton, Conjecticut 

Supr. of Shipbuilding

USN and Nav. Inspec. of Oranance

Newport News Shipbuilding

and Dry Dock Co.

Newport News, Virginia

(1)

Supr. of Shipbuilding

USi and Nav. Inspec. of Ordnance

Ingalls Shipouilding Corp.

Pascagoula, Kississippi

CO, U.S. Hav. Admin. Unit

KIT, Camoridge 39, wass.

Officer-in-Charge

Postgrad. School for liaval Officers

Webb Inst. of llav. Arch.

Crescent Beach Rd.

Glen Cove, L.I., H.I.

Supt., Nav. Gun Fastory

Washington 25, D.C.

Comm., Nav. Ordnance Test Sta.

China Lake, California

Attn: Physics Div. liechanics Div.

CO, Nav. Urdnance Test Sta. Underwater Ordnance Div. 3202 E. Foothill 3lvd. Pasadena 8, California Attn: Struc. Div.

$\mathrm{CO}$ and Director

U.S. Nav. Engin. Lxp. Station Annapolis, Iraryland

Supt. U.S. Hav. Postgrad. School lionterey, California

Comm. liarine Corps Schools

Quantico, Virginia

Attr: Dir., IIC Dev. Center

Comm Gen., USAF

Washington 25, D.C.

Attn: Res. and Dev. Div.

$\mathrm{CO}$, Air haterial Comiand Wright-Patterson AF, Oisio

Attn: HCREX-B

Structures iiv.

CO, USAF Inst. of Technology Wright-Patterson AFB, Ohio

Attn: Chief, Appl. ilech. Group
Director of Intelligence

Headquarters, USAF

Washington 25, D.

Attn: PV sr. (Air Targ. Div)

CO, A.F. Office Sci. Research

ashineton 25, D.C.

Atn: liechanics Div.

U,S. Atomic Energy Commission

Vashington 25, D,C.

Attn: Dir. of Research

Dir., Nat. Bur. of Standards

Vasington 25, D.C.

ittn: Div. of Wechanics

Engin. Nech, Sect.

Aircraft Structures

Corm., U.S. Coast uard

1300 t. St., in

asininton 25, D.C,

Attn: Chief, Test and Dev. Div.

U.S. Waritine ddministration

General Admin. Uffice $31 \mathrm{dg}$.

Lit G St., Nit

vashington 25, ע.C.

Attn: Chief, Div。 Prelim.

Desien

Nat. Aero, and Space Admin.

Lanfley lesearch ienter

Langley Iield, Virginia

Attn: Structures Div.

Wat. Aero. and Space Adrin.

1512 H St., .M.

Vashington 25, D.C.

Attn: Loads and Struc. Div.

Director, Forest Prod. Lab.

Hadison, Wisconsin

Federal Aviation Agency

iept. of Commerce

Uashington 25, D.C.

Attn: Chief, Air ingin. Div.

Chief, Air and

Equip. Div.

National Science Foundation

1520 H. St., Nit

i.ashineton, D.C.

General Dynamic Corp.

¿lectr. Joat ìiv.

Groton, Connecticut 

National Academy of Sciences 2101 Constitution Ave., Washington 25, D.C.

Attn: Dira, Corm. on Ships

Struc. iesign

Exec. Secy., Corm. on

Undersea arfare

Wewport Wews Shipbuilding and Dry Dock Co.

Newport Vews, Virginia

Ingalls Shipbuilding corp.

Pascagoula, Kississippi

Prof. Lynn S. Beedic

Fritz Lngineering Lab.

Lehigh University

Bethiehem, Penra.

Prof. R.L. Bisplinghofi

Eept. of Aero. kny neerine

iiassachusetts inst. of Techr.

Cambridge 39, ilassachusetts

Prof. H.!. BIeich

Dept. of Civ. Engineering

Columbia university

New York 27, Wew Pork

Prof. B.A. joley

Dept of Civ. tneineering

Columbia University

New Jork 27, Hew Pork

Dr. John F. Brahtz

Southern California Labs

Stanford Research Institute

820 Mission St.

South Pasadcna, California

Dr. D.O. Brush

Struc. Dept. 53-13

Lockheed Aircraft Corp.

Missile Syst. Iiv.

Sunnyvale, Califurniz

Prof. B. Budiansky

Dept. of Hech. Engineering

School Appl. Cciences

Harvard University

Camiridge 39, llassachusetts

Prof. Herbert Leresiewicz

Dept. of Civ. Engineering

Columbia University

632 H. 125th St.

Hew York 27, H. I.
Pror. D.C. Irucker, Chmn.

Div. of Engincering

Brom University

Providence 12, Rhode Island

(1)

Prof. John Duberg

Lept. of Civ. Engineering

university of Illinois

Urbana, Ilinois

Prof. J. Ericksen

Nech. ngineering Jent.

Johns Hoprins university

3altinore 18, liaryland

Prof. A.je Eringen

Dept. of nero Lngineering

Pundue University

(1) Lafarcte, Inciana

(1)

Pror. $\because$ Fluge

Dept. of Hech. Wngineering

stanford, California

Vir. I.. Goland, VP and Vir.

Couthwest researci cnstitute

8500 Culebra

San Antonio 6, Texas

Prof. J.N. Goodier

Dept of weck. -ngineering

Stanford University

Stanford, California

Prof. L.'. Goodman

:ngineering pporimental Sta.

University of itinnesota

linneapolis, liinnesota

Prof. H. Hetenyi

The Technical Institute

Northestern University

Ivanston, Illinois

Prof. P.G. Hodge

Dept. Of Mecharics

IIIinois Tnst. of Technology

Cricago 16, Illinois

Prof. H.J. Hoff, Head

Div. Aeronautical Engineering

Stanford University

Stanford, valifornia

Prof. W.H. Hoppmann, II

Dept. of Mechanics

Rensselaer Polytechnic Inst.

Iroy, ivew York 

Prof. Bruce G. Johnston.

University Of lichigan

Ann Arbor, Kichigan

(1)

Prof. J. Kempner

Dept. of hero, ngineering and Appl. Wechanics

Polytechnic Inst. of Brookijn

$333 \mathrm{Jay}$ st.

Brooklyn 1, $\because .$. .

Prof. H.L. Langhaar

Dept. of Theoretical and Applied Mechanics

University o: Illinois

Urbana, Illinois

Prof. B.J. Lazan, Director Engineering wperinental sts. University of sinnesota

liinneapolis 14 , Vinnesota

Pror. E.H. Lee

Div. of Appl. Hathematics

Brown University

Providence 12, Thode Island

Pror. George H. Lee, Dir. of hes. Rensselaer Polytechnic inst. Troy, N.Y.

Mr. S. Levy

GE Ilectr. Kesearch Lab.

3198 Chestnut St.

Philadelphia, Penna.

Prof. Paul Ijiecer

Geology Department

University of California

Berkeley L, California

Prof. Joseph Varin, Head. Dept. neineering lechanics

College of inin. and srch. Pennsylvania State Unive: Sity University Park, Penna.

Prof. :L. I. Sindlin

Dept. of Cir. ingineering

Columioia University

632 i. 125th st.

New York 27, licw York

Prof. Paul M. ilaghdi

Buildine $\mathrm{T}-$ ?

College of Engineering

University of California

Berkeley 4 , california
Prof. Uilliam A. lash

Dept of Lngineering lechanics

university of rlorida

Ciainesville, Elorida

Prof. it. . Semark, Head

:ent of jiv. ropineering

University of Illinois

Urbana, Iliinois

Prof. E. Orowan

Dept. of iech, incineering

liassachusetts institute of Tech.

Caroridoe 39, iassachusetts

Prof. tris Fhizlips

Lept. ol Giv. Angineering

15 Prosuect it.

Yale university

litw Haven, "onnecticut,

Frof. A. Prager, Chmn.

shys. ci. Council

irots University

Providence 12, Rhode Island

Pror. J.t.r. kadok

Lept. $O$ sero $n$ ineering and Apl. wechanics

Polytecinic Inst. of rooklyn

333 Jay st.

Brooklyn 1, n. .

Prof. w.L. Heiss

Inst. of tathematical Cciences

ilew rork university

4 Vasilington Place

lev York 3, 1?.Y.

Prop. $\therefore$ reissner

Lept. of a atrematics

riassachusetts Inst. of Technology

Canoridee 39, .assachusetts

Prof. … Sadoristry

Dept. of iechanj.cs

hennselaer polytechnic Inst.

Troy, : Hew York

Prof. jo. Shaffer

Le, $t$. of Mect. Lneineering

liev lork University

University deichts

Hew ioris 3 , H.Y.

Prof. J. Stallmejer

Dept. of Civ. Engineering

University of Illinois

Urban, Illinois 

Prof. Eli Sternberg

Dept. of Hechanics

Brown University

Providence 12, Rhode Island

(1)

Prof. T.Y. Thomas

Grad. Inst. Hath and Hech.

Indiana university

Bloomington, Indiana

Prof. 3.: Timashenko

School of neineering

Stanford University

Stanford, Califorria

(1)

Prof. A.S. Velestos

Dept of iiv. Engineering

University of Illinois

Urbana, Illinois

(1)

Dr. W. wenk

Southwest iesearch Institute 8500 Culbera id.

San Antonio, Iexas

Prof. Dana Young

Yale University

liew Haven, Connecticut

Prof. R.A. Di Taranto

Dept. of Hech. nginecring

Drexel Institute

32 nd and Chestnut Streets

Philadelphia, Penna.

Wr. H.r. Koopman, Jecy.

Welding res. Council

Enrinecring Founciation

$29 \therefore 3$ th st.

New York 18, N.Y.

Prof. ialter i.. Daniels

School of Engin. and Archit.

Howard University

Washington I, D.C.

Comm., (Code 753)

U.S. Naval Ordnance Test Sta. China Lake California

Attn: Techn. Library

Prof. J. . Cermak

Dept. of Civ. infineering

Colorado State University

port Collins, Colorado
$-6-$

Prof. … Iiall

Lert. of Civ. ngineering

universit: of zllinois

Uruar, Illinois

Lr. Hyman Sertin

Design Integration iept。

iughes Aircraft Co.

Culver City, California

Commander, WADD

Uright-?atterson $A F B$, Ohio

Attn: Wirc

WWMPS

WTEIDD

(1)

Cormandine officer

USIHIOEU

Kirtland Air Force Base

Albuquerque, Nen : Mexico

utn: Code 20

(Er. J.iv. Brennan)

(1) Legislative :eference Service

Library of iontress

ashington 25, “.

Attn: Ur. L erk

(1)

Ir. A. SOss

Areraft Niclear Propulsion Iept.

General lectric Co.

Cincinnati 15, Ohio

(1) Dr. F. Line

General ipplied Science Labs

Stewart and Kerrick Arenues

iestbury, L.I., H.

Commander dward Lconard

usst. Iavy Representative

IIT Lincoln Lab.

Lexington 73, hassachusetts

Prof. i. Pohle

Grad. Wath. Dept.

idelphi City, L.I., N.X.

Dr. Hartin Goldererg

tesearch Dept.

Grumann Aircraft

Betipage, L.I., H.I.

Prof. 3.D. Larmarajan

Aero pace ie.t.

(1) San Eiego State University

San ie o 15, California 

Professor R.P. Harrington, Head

Dept. of Aeronautical ingineering

University of Cincinnati

Cincinnati 21 , Ohio

Professor urene J. Brunelze, Jr.

Dept. of peronautical ingineering

Princeton University

Princeton, ilen Jersey 


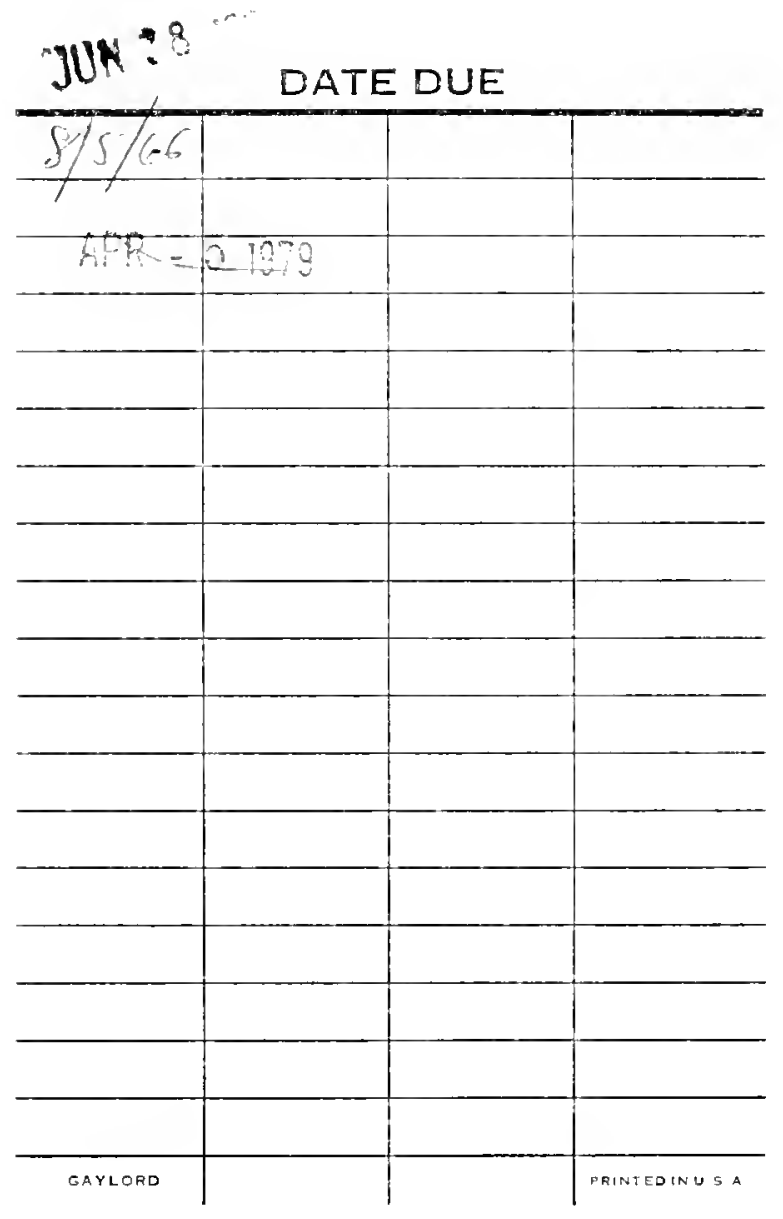




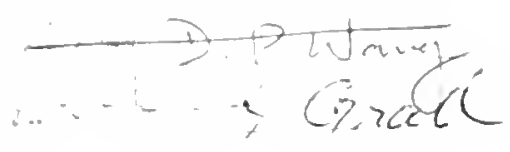

N.Y.U. Courant Institute of Mathematical Sciences 251 Mercer St. New York 12, N. Y. 
